\title{
Hypereosinophilic syndrome manifested as eosinophilic gastroenteritis and colitis in a patient undergoing hemodialysis
}

\author{
Eri Amano ${ }^{1}$, Taro Horino ${ }^{1 *}$, Osamu Ichii ${ }^{2}$, Satoshi Inotani, Tatsuki Matsumoto ${ }^{1}$, Kazu Hamada-Ode ${ }^{1}$, \\ Yoshiko Shimamura ${ }^{1}$, Kosuke Inoue ${ }^{1}$ and Yoshio Terada ${ }^{1}$
}

\begin{abstract}
Background: Hypereosinophilic syndrome (HES) consists of a group of disorders characterized by abnormal accumulation of eosinophils in the blood or peripheral tissues, independent of known secondary causes of eosinophilia. Clinical manifestations of HES are highly variable, ranging from asymptomatic eosinophilia to severe tissue damage and end-organ failure.

Case presentation: We herein present the case of a 65-year-old female with a 38-year history of hemodialysis who presented with lower leg pain, fever, skin eruption with leg edema, and diarrhea. Two months before admission, she underwent placement of a stent made of nickel and titanium for abdominal aortic stenosis. Lower leg pain occurred during hemodialysis, followed by fever, pedal edema with skin eruption, and diarrhea. Gastrointestinal endoscopy, colonoscopy, and biopsy histopathology revealed colitis with massive infiltration of eosinophils, compatible with eosinophilic gastroenteritis and colitis. The patient was treated with prednisolone at an initial dose of $40 \mathrm{mg}$ daily and later reduced to $10 \mathrm{mg}$ daily, after which her symptoms improved and her laboratory parameters normalized. She has not experienced a relapse after 1 year of follow-up.

Conclusions: Our case of HES manifested as eosinophilic gastroenteritis and colitis and was successfully treated with corticosteroids. Clinicians should consider the differential diagnosis of HES when faced with similar cases in order to effect timely and appropriate treatment.
\end{abstract}

Keywords: Hypereosinophilic syndrome (HES), Metal stent placement, Nickel allergy, Peripheral arterial disease (PAD)

\section{Background}

Hypereosinophilic syndrome (HES) is defined as a group of disorders characterized by abnormal accumulation of eosinophils in the blood or peripheral tissues. Clinical manifestations vary considerably, ranging from asymptomatic eosinophilia to severe tissue damage and endorgan failure. The prevalence of eosinophilia has been reported to vary from 13 to $52 \%$ in hemodialysis patients and can increase with time spent undergoing dialysis [1]. Eosinophilia from any other cause has also been reported to cause life-threatening reactions in patients undergoing hemodialysis due to the release of interleukins and

\footnotetext{
* Correspondence: horinott@yahoo.co.jp

${ }^{1}$ Department of Endocrinology, Metabolism and Nephrology, Kochi Medical School, Kochi University, Kohasu, Oko-cho, Nankoku, Kochi 783-8505, Japan Full list of author information is available at the end of the article
}

eosinophil peroxidase due to the degranulation of eosinophils [1]. Severe reactions to dialysis secondary to hypereosinophilia and the therapy provided for such patients have not been reported frequently [1]. We herein report a case of HES that manifested as eosinophilic gastroenteritis and colitis on long-term maintenance hemodialysis and was successfully treated with corticosteroids.

\section{Case presentation}

A 65-year-old female with a 38-year history of hemodialysis presented with lower leg pain, fever, skin eruption with leg edema, and diarrhea. Two months before admission, she had undergone placement of a stent made of nickel and titanium for abdominal aortic stenosis with lower leg pain during hemodialysis. "She received chronic maintenance hemodialysis with Vitamin E immobilized 
Table 1 Laboratory data at admission of our patient

\begin{tabular}{|c|c|c|c|}
\hline & & & (Reference range) \\
\hline \multicolumn{4}{|l|}{ CBC } \\
\hline $\mathrm{RBC}$ & 309 & $\times 10^{4} / \mu \mathrm{L}$ & $(435-555)$ \\
\hline $\mathrm{Ht}$ & 26.1 & $\%$ & $(40.7-50.1)$ \\
\hline $\mathrm{Hb}$ & 8.3 & $\mathrm{~g} / \mathrm{dL}$ & $(13.7-16.8)$ \\
\hline Plt & 25.4 & $\times 10^{4} / \mu \mathrm{L}$ & $(15.8-34.8)$ \\
\hline WBC & 27.4 & $\times 10^{3} / \mu \mathrm{L}$ & (3.3-8.6) \\
\hline neu & 49 & $\%$ & $(41.2-74.7)$ \\
\hline lym & 2 & $\%$ & $(21.2-51.0)$ \\
\hline mon & 1 & $\%$ & $(3.1-8.0)$ \\
\hline eos & 48 & $\%$ & $(0.2-4.8)$ \\
\hline bas & 0 & $\%$ & $(0.1-1.0)$ \\
\hline \multicolumn{4}{|l|}{ Proteinogram } \\
\hline $\lg G$ & 2540 & $\mathrm{mg} / \mathrm{dL}$ & $(870-1700)$ \\
\hline $\lg A$ & 147 & $\mathrm{mg} / \mathrm{dL}$ & $(110-410)$ \\
\hline $\lg M$ & 106 & $\mathrm{mg} / \mathrm{dL}$ & $(35-220)$ \\
\hline $\lg \mathrm{E}$ & 1913 & $\mathrm{IU} / \mathrm{mL}$ & $(<100.0)$ \\
\hline \multicolumn{4}{|c|}{ Serological examinations } \\
\hline CRP & 4.73 & $\mathrm{mg} / \mathrm{dL}$ & $(<0.14)$ \\
\hline ANA & $<40$ & $\times$ & $(<40)$ \\
\hline MPO-ANCA & $(-)$ & & $(-)$ \\
\hline PR3-ANCA & $(-)$ & & $(-)$ \\
\hline GBM Ab & $(-)$ & & $(-)$ \\
\hline sIL2R & 4834 & $\mathrm{U} / \mathrm{mL}$ & $(127-582)$ \\
\hline \multicolumn{4}{|c|}{ Blood chemistry } \\
\hline TP & 7.3 & $\mathrm{~g} / \mathrm{dL}$ & $(6.6-8.1)$ \\
\hline FBS & 89 & $\mathrm{mg} / \mathrm{dL}$ & (73-109) \\
\hline Alp & 350 & $\mathrm{U} / \mathrm{L}$ & $(106-322)$ \\
\hline t-Cho & 122 & $\mathrm{mg} / \mathrm{dL}$ & $(142-322)$ \\
\hline Y-GTP & 18 & $U / L$ & (13-64) \\
\hline t-Bil & 0.3 & $\mathrm{mg} / \mathrm{dL}$ & $(0.4-1.5)$ \\
\hline d-Bil & 0.1 & $\mathrm{mg} / \mathrm{dL}$ & $(<0.4)$ \\
\hline ChE & 147 & U/L & $(240-486)$ \\
\hline Glb & 5.1 & $\mathrm{~g} / \mathrm{dL}$ & $(2.2-3.4)$ \\
\hline Alb & 2.2 & $\mathrm{~g} / \mathrm{dL}$ & $(4.1-5.1)$ \\
\hline ALT & 13 & U/L & $(10-42)$ \\
\hline AST & 17 & $\mathrm{U} / \mathrm{L}$ & (13-30) \\
\hline LDH & 324 & $\mathrm{U} / \mathrm{L}$ & $(124-222)$ \\
\hline CPK & 159 & $\mathrm{U} / \mathrm{L}$ & (59-248) \\
\hline $\mathrm{SCr}$ & 5.6 & $\mathrm{mg} / \mathrm{dL}$ & $(0.65-1.07)$ \\
\hline BUN & 43 & $\mathrm{mg} / \mathrm{dL}$ & $(8-20)$ \\
\hline UA & 5.6 & $\mathrm{mg} / \mathrm{dL}$ & $(3.7-7.8)$ \\
\hline Amy & 51 & $U / L$ & $(44-132)$ \\
\hline $\mathrm{HbA1c}$ & 5.8 & $\%$ & $(4.6-6.2)$ \\
\hline
\end{tabular}

Table 1 Laboratory data at admission of our patient (Continued)

\begin{tabular}{|c|c|c|}
\hline & & (Reference range) \\
\hline \multicolumn{3}{|l|}{ Infection } \\
\hline $\mathrm{HCV} A b$ & $(+)$ & $(-)$ \\
\hline $\mathrm{HBs} \mathrm{Ag}$ & $(-)$ & $(-)$ \\
\hline \multicolumn{3}{|c|}{ 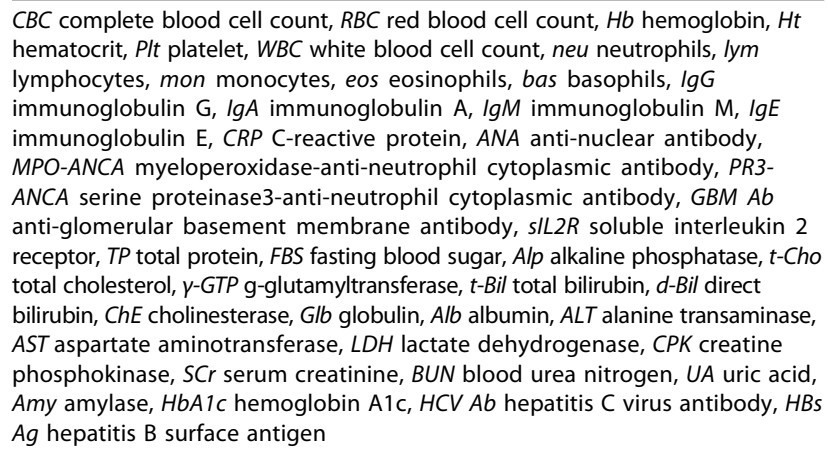 } \\
\hline
\end{tabular}

polysulfone dialyzer VPS-18HA ${ }^{\bullet}$ (AsahiKASEI, Tokyo, JAPAN) and heparin sodium as anticoagulant. The condition of hemodialysis did not change during her clinical course, and she has not indicated hypereosinophilia while performing the same hemodialysis condition so far."

After stent placement, her lower leg pain continued, and subsequently, fever, pedal edema with skin eruption, and diarrhea occurred. She was treated with meropenem hydrate $0.5 \mathrm{~g}$ daily after hemodialysis due to the initial suspicion of cellulitis. However, her symptoms progressed rapidly; therefore, she was transferred to our hospital.

On admission, physical examination revealed muscle weakness and pedal edema with eruption. As shown in Table 1, laboratory examination revealed elevated levels of C-reactive protein (CRP) $(4.73 \mathrm{mg} / \mathrm{dL})$ and white blood cell count (WBC) $(27,400 / \mu \mathrm{L})$ with eosinophils $(13,152 /$ $\mu \mathrm{L})$, hemoglobin $(\mathrm{Hb})(8.3 \mathrm{~g} / \mathrm{dL})$, and IgE $(1913.0 \mathrm{IU} / \mathrm{mL})$. Fecal examination revealed that occult blood was positive but parasites were negative. Tumor markers including carcinoembryonic antigen and $\alpha$-fetoprotein were all negative. Serological testings including anti-nuclear antibody, myeloperoxidase-anti-neutrophil cytoplasmic antibody, and serine proteinase3-anti-neutrophil cytoplasmic antibody were all negative. Bone marrow examination was performed to exclude chronic myeloid disorders and revealed no remarkable abnormalities. Abdominal computed tomography $(\mathrm{CT})$ scan revealed peripheral arterial disease (PAD) as well as the abdominal aortic stenosis with intra-aortic stent (Fig. 1). Echocardiogram and electrocardiography showed no remarkable findings (Fig. 2). Erythrocyte transfusion equivalent to $400 \mathrm{~mL}$ blood was performed for progression of anemia ( $\mathrm{Hb} 6.4 \mathrm{~g} / \mathrm{dL})$. Fever and skin eruption continued. One month after admission, diarrhea and melena occurred, and subsequently, anemia 


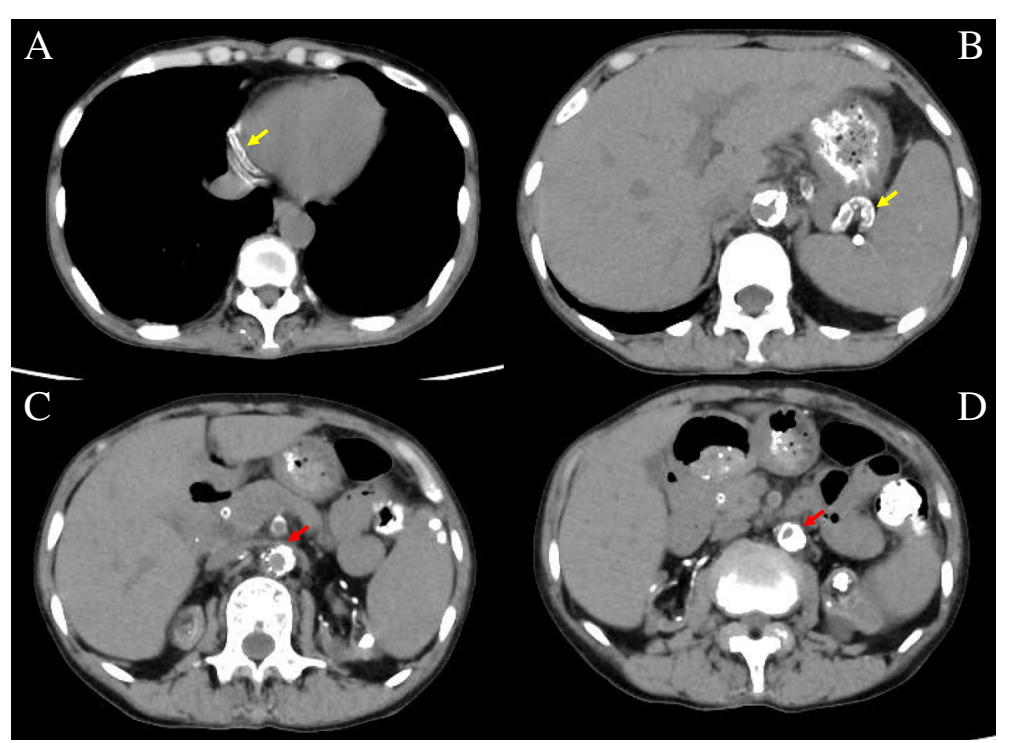

Fig. 1 Abdominal computed tomography revealing $\mathbf{a}$, $\mathbf{b}$ peripheral arterial disease (PAD) (yellow arrows) and $\mathbf{c}$, $\mathbf{d}$ abdominal aortic stenosis with intra-aortic stent (red arrows)

progressed. Her antibiotic treatment was changed to levofloxacin $250 \mathrm{mg}$ every other day; however, her symptoms did not change. Colonoscopy revealed colitis, and biopsy histopathology revealed colitis with massive infiltration of eosinophils, compatible with eosinophilic colitis (Fig. 3a, b). As shown in Fig. 4, prednisolone (PSL) $40 \mathrm{mg}$ daily was started, after which her symptoms, including fever and skin eruption, improved and her laboratory parameters, including CRP, WBC, and eosinophil count, normalized. PSL was then tapered to $5 \mathrm{mg}$ daily; however, the melena recurred. Gastrointestinal endoscopy revealed enteritis in the small intestine, and biopsy histopathology confirmed eosinophilic gastroenteritis (Fig. 3c, d). Therefore, PSL was increased to $10 \mathrm{mg}$ daily, after which her symptoms improved. After discharge, she was followed up in an outpatient clinic for 1 year without relapse.

\section{Discussion}

Eosinophilia is defined as an elevation in the absolute eosinophil count (AEC). Definition and classification of the severity of eosinophilia is shown in Table 2 [2-4]. First used in 1968 [5], the term "hypereosinophilic syndrome" was coined to describe this set of symptoms [6]. Subsequently, formal diagnostic criteria for HES were established in 1975, in which HES was defined as having no secondary causes of eosinophilia [7]. To date, with the accumulation of knowledge contributed by multiple researchers, not only have improved diagnostic techniques led to the identification of previously unrecognized causes of HES, but also the availability of effective therapies has led to a marked decrease in morbidity and mortality in patients with HES who are treated early. Therefore, HES has recently been categorized as a syndrome that includes

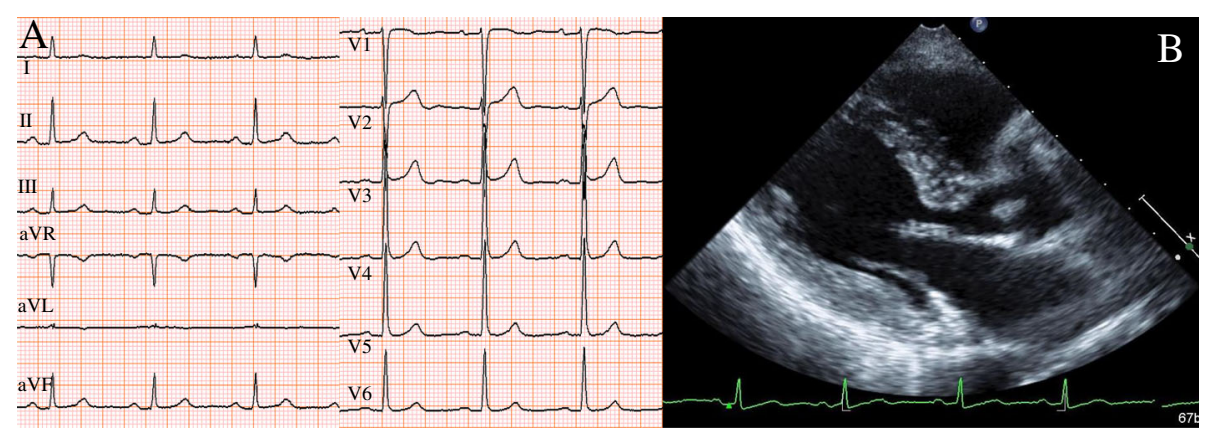

Fig. 2 The findings of echocardiogram and electrocardiography. a The echocardiogram revealed no remarkable findings. b Electrocardiography showed no remarkable abnormalities 


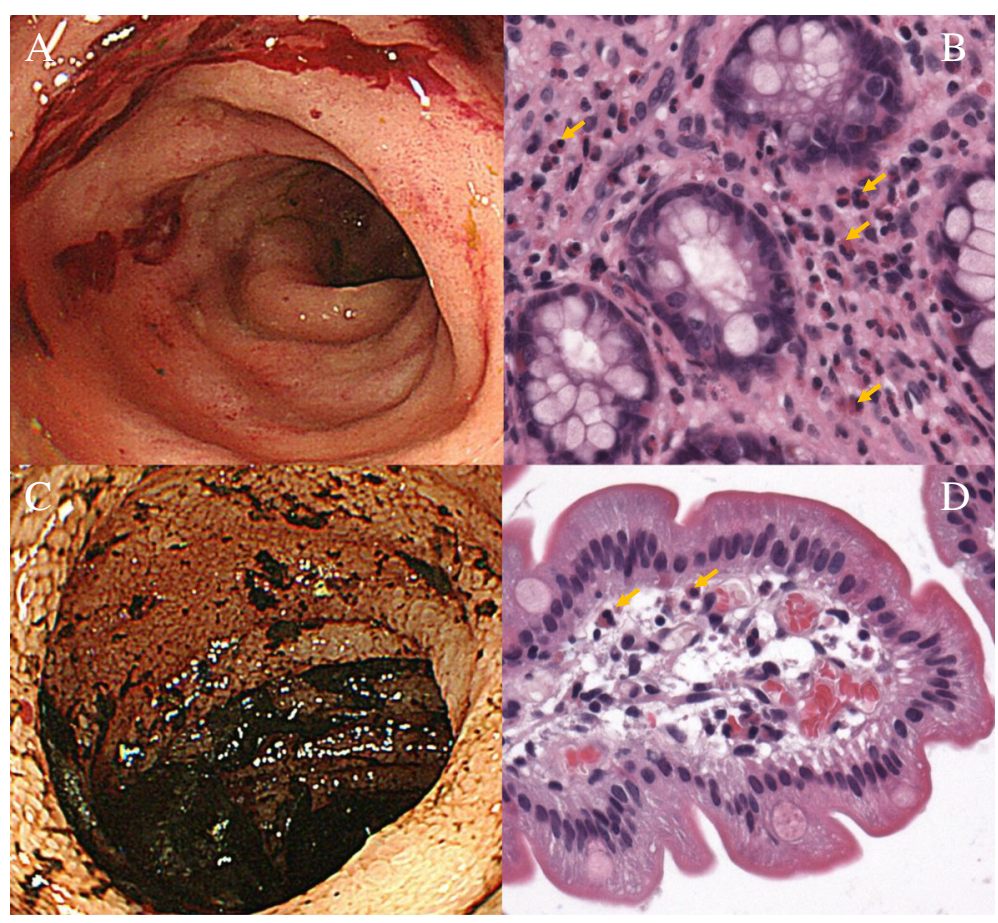

Fig. 3 The findings of endoscopy and biopsies. a Macroscopic finding of colonoscopy revealing colitis with bleeding. b Biopsy specimen of colonoscopy revealing massive infiltration of eosinophils (orange arrows) (periodic acid-Schiff, $\times 200$ ), consistent with eosinophilic colitis. c Macroscopic finding of endoscopy revealing duodenitis with bleeding. $\mathbf{d}$ Biopsy specimen of colonoscopy revealing massive infiltration of eosinophils (yellow arrows) (periodic acid-Schiff, $\times 200$ ), consistent with eosinophilic gastroenteritis

various pathological conditions previously identified as causes. This allows for early and prompt diagnosis with subsequent early intervention, which is needed for improving the prognosis of organ damage associated with HES. Now, HES is defined broadly as blood hypereosinophilia (HE) (AEC of $\geq 1500 / \mu \mathrm{L}$ ) and includes clinical manifestations attributable to eosinophilia or tissue HE with blood eosinophilia (AEC above the upper limit of normal for the reference laboratory) (Table 2) [8]. As described previously (shown in Table 3), HE has many differential diagnoses [8].

At a 2005 international consensus conference on HES treatment, a classification scheme was proposed that subdivided patients with HES into six clinically defined groups to facilitate treatment decisions [9]. This classification was refined in 2010 [10] and continues to be updated as our understanding of the relationship between this condition's etiology and response to therapy evolves [11]. HES is divided into the following six clinical variants (Table 2) [8]. Overlap HES, one of the clinical variants of HES, is defined as eosinophilic disease restricted to a single organ system, accompanied by peripheral eosinophilia $>1500 / \mu \mathrm{L}$ [8]. Eosinophilic gastrointestinal disorders (EGIDs), a group of rare differential diagnoses of HE (shown in Table 3) [8], are often categorized as part of this group. Patients with EGID may present with nausea, vomiting, diarrhea, abdominal pain, dysmotility, and failure to thrive, depending on the degree and location of the eosinophilic infiltration. Our patient was considered as having overlap HES, because her clinical manifestations showed EGID presenting as eosinophilic gastroenteritis and colitis.

HES of any etiology can cause serious, potentially life-threatening, complications, including cardiac involvement, thromboembolism, and neurologic manifestations. Although clinical and laboratory findings associated with aggressive disease and poor prognosis include AEC > $100,000 / \mu \mathrm{L}$, signs of congestive heart failure, and resistance to corticosteroid therapy, specific biomarkers of disease progression have not been identified [8]. Consequently, the decision to initiate urgent therapy depends on both the acuity and severity of the clinical presentation and the perceived risk of rapid progression [6].

When life-threatening manifestations are present or imminent, high-dose corticosteroid therapy should be initiated immediately $[6,8]$. The recommended dosing ranges from $1 \mathrm{mg} / \mathrm{kg}$ PSL to $1 \mathrm{~g}$ methylprednisolone depending on the severity of the clinical manifestations [8]. Intravenous administration should be considered to ensure adequate absorption in patients who are acutely ill 


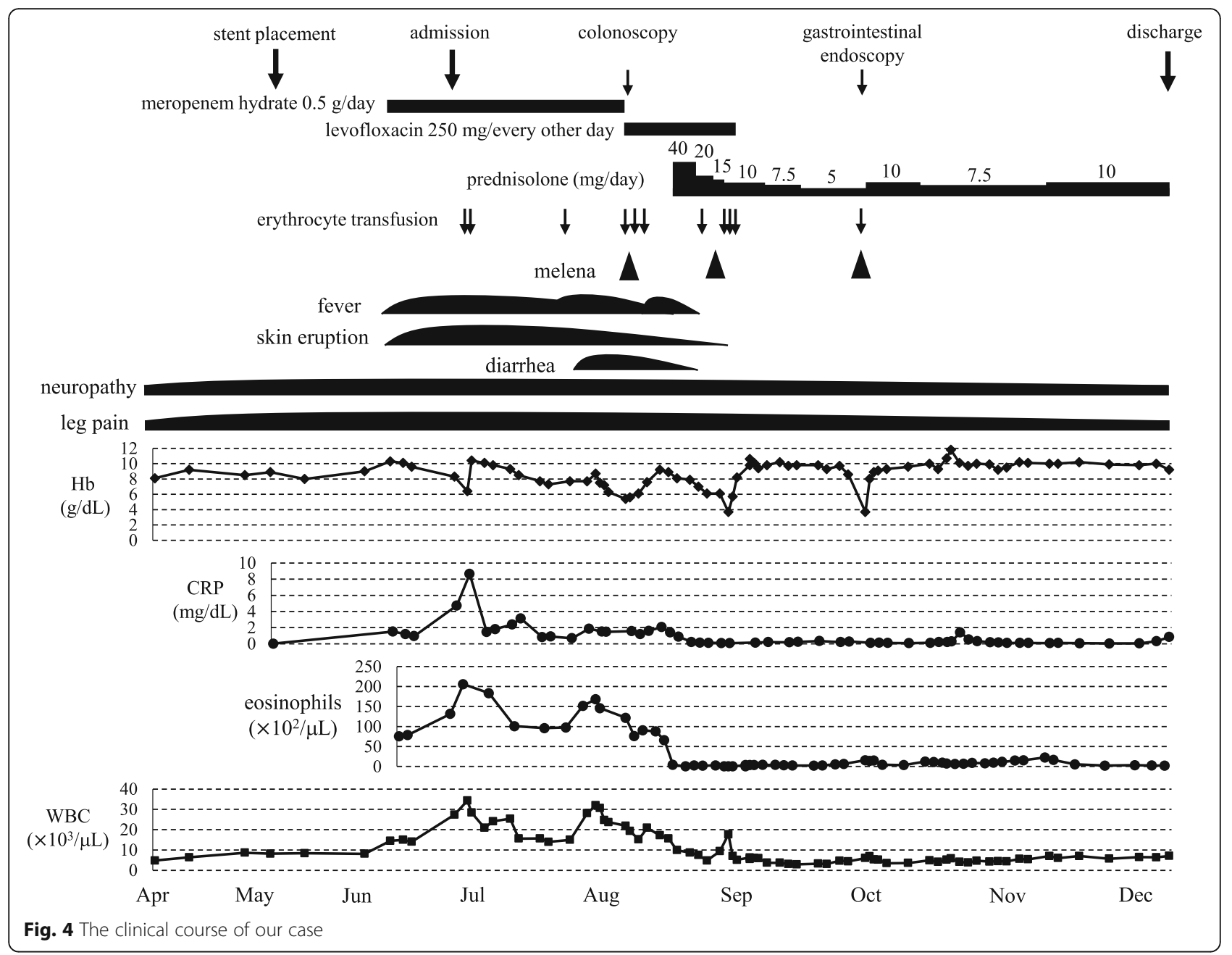

or have signs or symptoms of gastrointestinal involvement [8]. In a multicenter study including 188 HES patients, it was found that $81 \%$ had been initially treated with steroids. The median dose of PSL or an equivalent steroid was $40 \mathrm{mg}$ daily. Nearly $75 \%$ were on maintenance steroids for an extended period, with an average dose of $10 \mathrm{mg}$ PSL daily. The duration of therapy ranged from 2 months to 20 years. Eighty-five percent of the patients on steroid monotherapy had a partial or complete remission within 1 month of therapy initiation [12]. In our case, although steroid therapy was very effective, it was necessary to continue $10 \mathrm{mg}$ of oral PSL to ensure complete resolution because bleeding recurred when oral PSL was reduced to a lower dosage.

To date, seven cases with eosinophilia and clinical symptoms due to nickel including our case had been described [13-18]. Gray reported the first case of a patient who developed eosinophilia due to ingestion of a nickel coin and presented with Loffler's syndrome, transient migratory infiltrates associated with peripheral eosinophilia [13]. Four cases of occupational asthma with HE associated with exposure to nickel dust have been previously reported [14-17]. These five cases had transient mild eosinophilic pneumonia [13, 14] or asthma [15-17] that could be treated with low-dose corticosteroid. Meanwhile, Fung et al. reported a case of fulminant $\mathrm{HE}$ and eosinophilic myocarditis triggered by the nickel in implantable cardioverter-defibrillator components superimposed on advanced non-ischemic dilated cardiomyopathy, who eventually needed cardiac transplantation [18]. Previous reports have suggested that organ complications of eosinophilia due to nickel cause damage to organs close to the exposure site and that the severity also correlates with the intensity of the exposure (Table 4). Although symptoms in the previous cases developed in a short period, the timing of the onset of eosinophilia was unknown and symptoms progressed slowly in our case. However, eosinophilia was confirmed under the mucosa of the stomach and colon, which is downstream of the stent position of the abdominal aorta. We suspected that eosinophils 
Table 2 Definition and classification of eosinophilia [1-3] and hypereosinophilic syndrome (HES) [7]

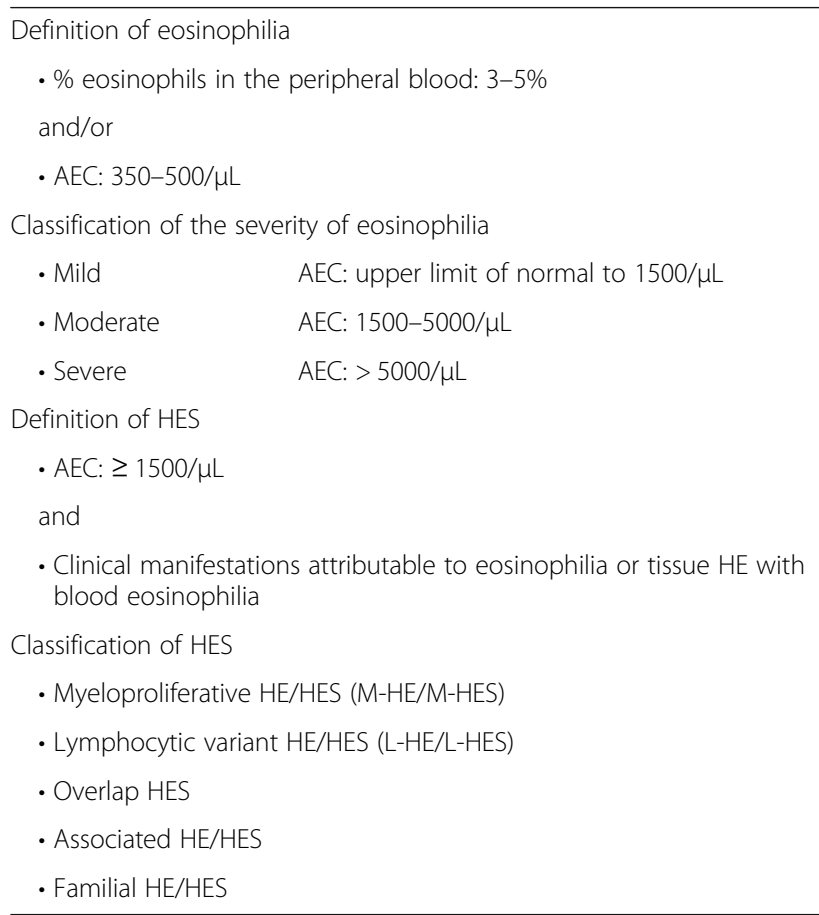

AEC absolute eosinophil count, $H E$ hypereosinophilia

could be sprayed along the bloodstream, so the symptom onset might progress slowly. Likewise, in our case, deterioration of symptoms and increase of leukocytes accompanying a prominent eosinophilia increase were observed after insertion of an indwelling stent, and these symptoms were improved by steroid therapy. Thus, it was suspected that stent placement, in particular a reaction to nickel in the stent material, might have caused the HES in our case. Similar to the case reported by Fung et al. [18], we considered that, in our case, the degree of eosinophilia and the severity of its complication became severe because of the indwelling nickel stent. Unfortunately, removal of the stent was technically impossible, and the reaction to nickel could not be confirmed by an allergy test because the patient was undergoing steroid therapy.

In our case, the referral doctor initially diagnosed eosinophilic granulomatosis with polyangiitis (EGPA) from leg pain and eosinophilia. However, our patient had been receiving dialysis therapy for a long time, and CT findings revealed severe calcification of systemic arterial walls, consistent with PAD. Therefore, although subjective symptom progression was observed with systemic inflammation after stent placement, the leg pain was assumed to be a symptom mainly associated with PAD. Even after stent placement, the leg pain persisted mildly, especially during dialysis, and vasculitis was not proven histologically. Therefore, as mentioned above, the final diagnosis of our case was designated as overlap HES. Considering these facts, we suggest that, because elderly patients with underlying diseases usually have various complications, clinicians should be wary of ascribing a disease to a single pathological condition and consider the coexistence of multiple diseases, even when symptoms point to a single condition.

\section{Conclusions}

Here, we report an unusual case of HES that manifested as eosinophilic gastroenteritis and colitis caused by

Table 3 Differential diagnoses of hypereosinophilia [8]

\begin{tabular}{ll}
\hline Category & Examples \\
\hline - Allergic disorders & Asthma, atopic dermatitis \\
- Drug hypersensitivity & Eosinophilia-myalgia syndrome, DRESS, interstitial nephritis, eosinophilic hepatitis \\
- Infection & \\
- Helminthic & Strongyloidiasis, trichinellosis, filariasis, schistosomiasis, hookworm \\
- Ectoparasitic & Scabies, myiasis \\
- Protozoan & Isosporiasis, sarcocystis myositis \\
- Fungal & Coccidiodomycosis, allergic bronchopulmonary aspergillosis, histoplasmosis \\
- Viral & HIV \\
- Neoplasia & Leukemia, lymphoma, adenocarcinoma \\
- Immunologic disorders & \\
- Immunodeficiency & DOCK8 deficiency, hyper-lgE syndrome, Omenn's syndrome \\
- Autoimmune and idiopathic & Sarcoidosis, inflammatory bowel disease, IgG4 disease, other connective tissue diseases \\
- Miscellaneous & Radiation exposure, cholesterol emboli, hypoadrenalism, IL-2 therapy \\
- Rare eosinophilic disorders & Idiopathic HES, EGPA, EGIDs \\
\hline
\end{tabular}

DRESS drug reaction with eosinophilia and systemic symptoms, HIV human immunodeficiency virus, DOCK8 dedicator of cytokinesis 8 , IgE immunoglobulin E, IgG4 immunoglobulin G4, IL-2 interleukin-2, EGPA eosinophilic granulomatosis with polyangiitis, EGIDs eosinophilic gastrointestinal disorders 
Table 4 Previous reports of hypereosinophilia due to nickel [13-18]

\begin{tabular}{|c|c|c|c|c|c|c|c|c|c|}
\hline No. & Author & Year & Age & Gender & Cause & Clinical manifestations & Treatment & Outcome & Ref. \\
\hline 1 & Gray J (Canada) & 1982 & 67 & Female & $\begin{array}{l}\text { Ingestion of nickel } \\
\text { coin }\end{array}$ & Eosinophilic pneumonia & Coin removed & Improved & [13] \\
\hline 2 & Toyoshima M (Japan) & 1994 & 16 & Male & $\begin{array}{l}\text { Occupationally } \\
\text { exposed }\end{array}$ & Eosinophilic pneumonia & Corticosteroid (i.v., oral) & Improved & [14] \\
\hline 3 & $\begin{array}{l}\text { De Hauteclocque C } \\
\text { (France) }\end{array}$ & 2002 & 40 & Male & $\begin{array}{l}\text { Occupationally } \\
\text { exposed }\end{array}$ & Asthma & n.d. & n.d. & [15] \\
\hline 4 & Marraccini P (Italy) & 2008 & 43 & Female & $\begin{array}{l}\text { Occupationally } \\
\text { exposed }\end{array}$ & Asthma & n.d. & n.d. & [16] \\
\hline 5 & Song GW (Korea) & 2013 & 34 & Male & $\begin{array}{l}\text { Occupationally } \\
\text { exposed }\end{array}$ & Asthma & $\begin{array}{l}\text { Corticosteroid (inhaled), } \\
\text { job change }\end{array}$ & Improved & [17] \\
\hline 6 & Fung E (USA) & 2016 & 45 & Male & ICD & Eosinophilic myocarditis & Corticosteroid (i.v., oral) & Not improved (C.T.) & [18] \\
\hline 7 & Our case (Japan) & 2018 & 65 & Female & $\begin{array}{l}\text { Nickel stent } \\
\text { replacement }\end{array}$ & EGIDs & Corticosteroid (oral) & Improved & \\
\hline
\end{tabular}

ICD implantable cardioverter-defibrillator, C.T. cardiac transplantation, EGIDs eosinophilic gastrointestinal disorders, i.v. intravenous, ref. reference, n.d. not described

nickel stent replacement therapy in a patient undergoing hemodialysis. Early identification of and medical intervention for her HES resulted in a successful outcome. We conclude, therefore, that it is vital for clinicians to perform differential diagnoses considering the possibility of HES in order to effect timely and appropriate treatment. Moreover, it is important that data from similar cases be accumulated and future studies conducted to improve the prognoses of HES patients.

\section{Abbreviations}

AEC: Absolute eosinophil count; CRP: C-reactive protein; CT: Computed tomography; EGIDs: Eosinophilic gastrointestinal disorders; Hb: Hemoglobin; HE: Hypereosinophilia; HES: Hypereosinophilic syndrome; PAD: Peripheral arterial disease; PSL: Prednisolone; WBC: White blood cell count

\section{Acknowledgements}

The authors would like to express their sincere thanks to the medical staff of Kochi Medical School Hospital, Nankoku, Japan.

\section{Availability of data and materials}

The data and materials were all included in the manuscript.

\section{Authors' contributions}

$\mathrm{EA}, \mathrm{TH}, \mathrm{OI}, \mathrm{SI}, \mathrm{TM}, \mathrm{KH}-\mathrm{O}, \mathrm{YS}, \mathrm{Kl}$, and $\mathrm{YT}$ provided information on the discussion and treatment of the patient. EA, $\mathrm{TH}$, and $\mathrm{OI}$ collected the data and wrote the manuscript. All authors read and approved the final manuscript.

\section{Ethics approval and consent to participate}

According to the Ethical Guidelines for Medical and Health Research involving Human Subjects in Japan, ethical approval is not required for case reports.

\section{Consent for publication}

Written informed consent was obtained from the patient for the publication of this case report and any accompanying test results.

\section{Competing interests}

The authors declare that they have no competing interests.

\section{Publisher's Note}

Springer Nature remains neutral with regard to jurisdictional claims in published maps and institutional affiliations.

\section{Author details}

'Department of Endocrinology, Metabolism and Nephrology, Kochi Medical School, Kochi University, Kohasu, Oko-cho, Nankoku, Kochi 783-8505, Japan.

'Laboratory of Anatomy, Department of Biomedical Sciences, Graduate School of Veterinary Medicine, Hokkaido University, Kita 18, Nishi 9, Kita-Ku, Sapporo 060-0818, Japan.

Received: 2 February 2018 Accepted: 29 August 2018

Published online: 26 September 2018

\section{References}

1. Nayak-Rao S. A patient with hemodialysis intolerance and hypereosinophilia. Saudi J Kidney Dis Transpl. 2015;26:366-7.

2. Gotlib J. World Health Organization-defined eosinophilic disorders: 2014 update on diagnosis, risk stratification, and management. Am J Hematol. 2014;89:325-37.

3. Brigden M, Graydon C. Eosinophilia detected by automated blood cell counting in ambulatory North American outpatients. Incidence and clinical significance. Arch Pathol Lab Med. 1997;121:963-7.

4. Rothenberg ME. Eosinophilia. N Engl J Med. 1998;338:1592-600.

5. Hardy WR, Anderson RE. The hypereosinophilic syndromes. Ann Intern Med. 1968:68:1220-9.

6. Curtis C, Ogbogu P. Hypereosinophilic syndrome. Clin Rev Allergy Immunol. 2016;50:240-51.

7. Chusid MJ, Dale DC, West BC, Wolff SM. The hypereosinophilic syndrome: analysis of fourteen cases with review of the literature. Medicine (Baltimore). 1975;54:1-27.

8. Klion AD. How I treat hypereosinophilic syndromes. Blood. 2015;126: 1069-77.

9. Klion AD, Bochner BS, Gleich GJ, Nutman TB, Rothenberg ME, Simon HU, et al. The Hypereosinophilic Syndromes Working Group. Approaches to the treatment of hypereosinophilic syndromes: a workshop summary report. J Allergy Clin Immunol. 2006:117:1292-302.

10. Simon HU, Rothenberg ME, Bochner BS, Weller PF, Wardlaw AJ, Wechsler $M E$, et al. Refining the definition of hypereosinophilic syndrome. J Allergy Clin Immunol. 2010;126:45-9.

11. Valent $P$, Klion AD, Horny HP, Roufosse F, Gotlib J, Weller PF, et al. Contemporary consensus proposal on criteria and classification of eosinophilic disorders and related syndromes. J Allergy Clin Immunol. 2012; 130:607-12. e9

12. Ogbogu PU, Bochner BS, Butterfield JH, Gleich GJ, Huss-Marp J, Kahn JE, et al. Hypereosinophilic syndromes: a multicenter, retrospective analysis of clinical characteristics and response to therapy. J Allergy Clin Immunol. 2009:124:1319-25. e3

13. Gray J. Löffler's syndrome following ingestion of a coin. Can Med Assoc J. 1982;127:999-1000.

14. Toyoshima M, Sato A, Taniguchi M, Imokawa S, Nakazawa K, Hayakawa H, et al. A case of eosinophilic pneumonia caused by inhalation of nickel dusts. Nihon Kyobu Shikkan Gakkai Zasshi. 1994;32:480-4. Article in Japanese 
15. De Hauteclocque C, Morisset M, Kanny G, Kohler C, Mouget B, MoneretVautrin DA. Occupational asthma due to hard metals hypersensitivity. Rev Mal Respir. 2002;19:363-5. Article in French

16. Marraccini $\mathrm{P}$, Cantone $\mathrm{L}$, Previdi M, Patrini $\mathrm{L}$, Costamagna P. Respiratory allergy to nickel. Description of an atypical clinical case. G Ital Med Lav Ergon. 2008;30:139-41. Article in Italian

17. Song GW, Ban GY, Nam YH, Park HS, Ye YM. Case report of occupational asthma induced by polyvinyl chloride and nickel. J Korean Med Sci. 2013;28: $1540-2$.

18. Fung E, Fong MW, Correa AJ, Yoon AJ, Grazette LP. Fulminant eosinophilic myocarditis following ICD implantation in a patient with undisclosed nickel allergy. Int J Cardiol. 2016;203:1018-9.

Ready to submit your research? Choose BMC and benefit from:

- fast, convenient online submission

- thorough peer review by experienced researchers in your field

- rapid publication on acceptance

- support for research data, including large and complex data types

- gold Open Access which fosters wider collaboration and increased citations

- maximum visibility for your research: over $100 \mathrm{M}$ website views per year

At BMC, research is always in progress.

Learn more biomedcentral.com/submissions 